\title{
Students discussing their mathematical ideas: the role of the teacher
}

\author{
Monique Pijls • Rijkje Dekker
}

Received: 28 September 2009 /Revised: 25 September 2010 /Accepted: 3 April 2011 / Published online: 1 December 2011

C The Author(s) 2011. This article is published with open access at Springerlink.com

\begin{abstract}
This article adds to current research on enhancing student discourse in mathematics teaching specifically in secondary schools but with equal relevance to elementary schools. Three mathematics teachers in secondary education were confronted with the question of how to encourage students to discuss their work with each other in the daily practice of their mathematical lessons. In response to this question the teachers devised three different approaches to encourage student discourse. One of the teachers chose to experiment with another setting to perform mathematical tasks that involved students working together on a group test. The second teacher experimented with a new kind of help when students were working on their maths tasks and asked for assistance. The third created a new setting in which the teacher (temporarily) did not provide mathematical hints and the students had to solve their own problems. The three teachers were very motivated, but they all had difficulties in not giving explanations themselves when supporting their students in their collaborative mathematical learning. They found that temporarily diminishing their product help stimulated discussion between students. It also became clear that the process of teacher reflection and follow-up discussions with the researcher/observers promoted changes of practice.
\end{abstract}

Keywords Mathematics $\cdot$ Teacher $\cdot$ Collaborative learning $\cdot$ Process help

The research was carried out while Monique Pijls was at the Research Institute of Child Development and Education, University of Amsterdam

M. Pijls $(\bowtie)$

Centre of Expertise for Creative and Effective Science Education Bèta-boost, Amsterdam, The Netherlands

e-mail: monique@beta-boost.nl

R. Dekker

Research Institute of Child Development and Education, University of Amsterdam, Amsterdam, The Netherlands

e-mail: r.dekker@uva.nl 


\section{Introduction}

The role of the teacher in realising discussions between students

Currently in Dutch mathematical classrooms there is an emphasis on students working independently on tasks. They mostly sit in pairs, but work on different assignments and teachers rarely stimulate discussion between students. Research shows that students working in that independent setting risk having insufficient opportunity to put their thoughts into words and discuss the maths they are trying to learn (Stigler and Hiebert 1999). In our previous studies we have conducted research into collaborative learning of mathematics, that focused on the role of the teacher to stimulate discussion between students (Dekker and Elshout-Mohr 2004; Pijls 2007). We have compared two types of help the teacher could offer in guiding students working collaboratively on mathematical problems and their effect on mathematical level-raising within the problem-solving process (assessed by pre and post tests). In these previous studies one teacher provided product help by responding to students' questions by giving appropriate mathematical hints. The other teacher provided process help by focusing on the process of interaction and explicitly stimulating students to perform key activities. There was clear evidence that teachers who stimulated discussion between the students, while keeping their content help very restricted (process help), were as successful in regard to mathematical level-raising, and in some situations more successful, than teachers who concentrated on student product and gave content help (product help). It became clear that teachers had difficulty stimulating discussions between students without providing mathematical help themselves. That is why, in this study, we want to reconsider process help and discover if teachers have other strategies in their daily repertoire to enhance discussions between students.

In the mathematical learning process of students we consider level-raising as the transition from students' initial perception of a situation or problem, based on prior knowledge and ideas, towards a conceptual perception of that problem or situation. Reflection on their ideas is a central activity for students attaining mathematical level-raising (Freudenthal 1973). The key issue is to ensure that students express their ideas in order to effectively develop mathematical concepts (Dekker and Elshout-Mohr 1998). This can be effectuated by discussions between students in small-group work. With mathematical discussions we mean discussions, in which students show each other their mathematical (thinking) work, explain it, justify it and reconstruct their (thinking) work, as described as key activities in the process model of Dekker and Elshout-Mohr (1998). Students can provoke these key activities by asking each other to show and explain their work, and by giving critique. These activities are described as regulating activities in the process model. The process model is presented and described in Dekker and Elshout-Mohr (1998). A summary is presented in Table 1 which shows the regulating activities and key activities in students' interactions that enhance mathematical level-raising.

In Dutch mathematics education the learning materials are developed for independent learning, with a focus on individual learning. In our previous research projects (Dekker and Elshout-Mohr 2004; Pijls 2007) we developed learning materials for collaborative learning. Characteristics of these learning materials are 
Table 1 Key activities and regulating activities

Regulating activities

Students ask each other to show their work

Students ask each other to explain their work

Students critique each other's work
Key activities

Students show each other their work

Students explain their work to each other

Students justify their work

Students reconstruct their work

that the problems are realistic (which means that they are meaningful for the students), complex in the sense that different abilities are needed to solve them, ask for construction of something (to make thinking visible) and aim at level-raising (Dekker et al. 2004). Also grouping students with some difference in level will stimulate discussion (Webb 1991).

The guidance and support provided by the teacher is essential in encouraging students to discuss and develop their ideas with each other, both in guiding wholeclass discussions and by stimulating students to interact with each other during group work (Hoek 2007; Palha 2008; Walshaw and Anthony 2008). In a whole-class setting teachers may establish a social norm for their lessons; for instance, they expect their students to explain their work to each other and to be critical towards each other's work (Wood 2001). Hodge (2008) showed in her research that a maths teacher can let students view mathematics as a subject where the performance of key activities is essential. She observed the lessons of students in two primary classes and interviewed the students regarding their mathematical experiences. The teachers in the two classes organised their lessons in contrasting ways. In one classroom students commented that they followed the instructions and the explanations of the teacher and in the other classroom students mentioned expressing their own thinking and listening to others as essential for the mathematics learning process.

Practices in which teachers ask their students to further explain their work appear to be effective for students' explanations and mathematical discussions. Webb et al. (2008) examined for three teachers the relationship between teacher behaviour (whole-class and group work), student interaction during group work and student achievement. During discussion with the whole class, all three teachers in this study asked students to explain how they solved a mathematical problem, but the teachers differed in whether or not they asked for further explanation. The teachers also differed in how often they asked students to explain their work during pair-share. These differences showed a strong correspondence with the extent to which students explained to each other during collaborative conversations, and students' explanations were positively correlated to student achievement. It seems that during group work, students mirror the teacher-student interactions. A whole-class discussion then is an essential moment for modelling the performance of regulating activities and key activities.

The question is: How can teachers adopt behaviour and strategies to encourage their students to discuss their work? Gillies and Khan (2008) taught primary school teachers specific communication skills to challenge students' cognitive and metacognitive thinking during cooperative learning. These teachers received 
additional information on how to promote discussion during their small-group activities. The focus was essentially on strategies that evoke the expression of students' own thinking and the explaining of their ideas, as well as asking their peers to do so (key activities and regulating activities). The researchers found that students of these teachers provided more elaborations and obtained higher test scores than their peers whose teachers had not had this specific training but more general training on cooperative learning.

Daily practice in mathematics education

Although specific training of teachers on collaborative learning may be effective, other research shows that, for teachers, effectuating discussions between students is not so evident in daily practice (Stigler and Hiebert 1999). During group work teachers usually walk through the classroom and respond to students' questions. The question is how, when confronted with a question, can teachers stimulate students in their learning process, by giving appropriate mathematical hints, or by focussing on the process of interaction between students and explicitly stimulating students to perform key activities? Dekker and Elshout-Mohr (1998) discerned these two types of teacher help as product help and process help. Process help led to more mathematical level-raising for students in pre-university education. Whether it did so for students in higher vocational education was not clear (Pijls 2007). Students in this type of education had considerable difficulty with collaborative investigations and they expected the teacher to give more explanations. However, there were indications that process help and discussion with their peers encouraged students to think more about their work. Apparently, the optimal way of guiding students' mathematical discussions varies for different types of secondary education. Ideally, teachers should provide both product help and process help. However, the predominant way of giving help to students working on mathematical tasks is product help. The reason for this is not completely clear. Perhaps, with the examination goals in mind, teachers may abandon their focus on students' own explanations and switch to providing mathematical information (Peressini and Knuth 1998).

There are several ways in which a teacher may address students' mathematical thinking in a cooperative-learning classroom. In their study, Ding et al. (2007) distinguished three categories of teacher interventions: a) teachers' guidance focussing on the learning goal and students' cognitive obstacles, b) promoting student thinking, and c) encouraging high-level peer discussion. In a study of cooperative lessons in six mathematics classes they observed the occurrence of those activities in the lessons and found that teachers rarely used students' errors as a springboard for further learning. The one teacher who did do so insisted (in a wholeclass discussion) on further explanation of the misunderstanding, instead of reconstruction by "the right answer." The phenomenon whereby students adopt an (other) answer from a peer without explaining it was observed by others, for instance when students consider their peers as experts (Amit and Fried 2005; Pijls et al. 2007a). A further observation by Ding et al. (2007) was that two of the six teachers intensively stimulated the students to explain their work to each other, but that the majority mainly focussed on individual student questions (even during group work) and hence missed opportunities for encouraging peers to perform key activities. They mention that "teachers are often so occupied interacting with many individual 
students that they neglect peer interaction" (Ding et al. 2007; p. 172) and conclude that teachers should use peer resources effectively.

Although research provides evidence for the importance of explanations and mathematical discussions between students, it is still not common for most teachers to explicitly encourage students to explain their own work in the daily practice of their lessons. In our research we explicitly engage the teacher as an expert in developing a learning environment in which students have mathematical discussions with one another. We wanted to gain insight into the various techniques that teachers may use to evoke mathematical discussions between students.

\section{Method}

Our research question was:

How can teachers realise mathematical discussions between students in their daily practice?

We defined "mathematical discussions between students" as "students performing key activities," that is, students showing, explaining, justifying and reconstructing their work. The study described in this article consists of the analysis of three case studies with various teachers, classes and mathematical content to be learned in secondary education.

The organisation of the three case studies was similar; each study consisted of four parts: a typical lesson, discussion of that lesson, an experimental lesson and its evaluation. One of the researchers visited the teachers' mathematics lessons, lessons which were typical of their daily practice. As we had informed the teachers beforehand, we observed whether the students discussed their mathematical work, that is, whether they performed key activities (to show, explain, justify, reconstruct one's work). We also observed how the teachers' behaviour stimulated or hindered the performance of these key activities. Immediately after each lesson, the researcher interviewed the teacher for between 30 and $60 \mathrm{~min}$. In this interview the teacher was confronted with the researcher's observations regarding discussions between students. The teacher was then asked how he or she could increase discussions between students. The teacher was encouraged to formulate his/her own ideas for new practices, and the researcher mentioned the possibility of providing process help, that is, temporarily explicitly not providing mathematical hints. An action plan for another lesson, one week later, was prepared. This next lesson, the experimental lesson, was observed by the researcher. In an interview immediately after the lesson, the teacher evaluated this experimental lesson on the aspect of students' discussions during pair-share and group work.

We engaged both a beginning teacher (3 years' teaching practice) and two experienced (more than 10 years' teaching practice) mathematics teachers, as we considered some basic routine in teaching to be essential, but we also took into account that too much experience could hamper the learning of new teaching strategies. All three teachers had some experiences with collaborative learning and knew about the difficulties of increasing discussions between students. They were very motivated to take part in the study. 


\section{Data collection}

Data collection consisted of audio recordings of whole-class discussions and discussions within small groups of students. Observation notes were collected by the researchers (both authors), focussing on how mathematical discussions were evoked by the teacher's behaviour (way of offering help to the students and the timing of whole-class explanation) and other factors, such as the learning materials and the composition of the groups. Audio recordings of the interviews with the teachers were also collected.

\section{Data analysis}

The audio recordings of the small groups of pupils were analysed for the occurrence of key activities. An example will be given in case III. The observation notes and interview recordings were analysed for teachers' actions and the impact on mathematical discussions with the process model. Regulating activities (to ask to show work, to ask to explain work, to criticize) and key activities (to show, to explain, to justify, to reconstruct one's work) were identified in students' activities. The teachers' actions were analysed both on process help and product help. We also determined teacher behaviour other than process help for fostering key activities between students. The inter-observer reliability was addressed as follows: The analysis of each teacher was performed by one researcher (author) and discussed with two researchers (authors). There was strong agreement on the interpretation of the observations.

\section{Results of Case I: Isa experiments with group tests}

Isa is a maths teacher in a new school, which is based on principles of a learning community. Collaboration, interaction and learning together are highly valued and important on all levels. Students of different school levels are heterogeneously mixed, but they can do tasks at different levels. At the moment, Isa is the only maths teacher. Originally she was a teacher in primary education, and before that she taught in lower secondary education. For Isa, the connection of mathematics with daily life is very important. She was very motivated to take part in this experiment on mathematical discussions between students, because she (and her colleagues) experienced that students do not accomplish their collaborative assignments very well.

\section{Isa's typical lesson}

The atmosphere in the classroom is relaxed. Isa is sitting on her chair in front of the classroom and the students are sitting in groups of 3,4 or 7 students. She starts the lesson with an introduction on practical matters. Then she asks the students to take a new sheet of paper and draw a margin. Then she starts with a whole-class conversation about sizes: "If I fill this little bucket with sand, how much will it contain?" Students are giving answers; Isa also honours a "wrong answer" by saying 
"I think that is a very logical remark." She sometimes explicitly asks students to show their work, and asks to hear from certain groups: "Wait a minute; I first want to hear this group." She asks students to explain their work: "How do you know that?" "Are you sure there are 1000?" In this whole-class setting, Isa stimulates students to show and to explain their work to her.

Then students are working on assignments independently and when they have a question, they may walk to Isa's desk. She sometimes refers students to each other for explanation, if a student asks a question and another student asks the same question a little later. In general, peers sitting next to each other are not collaborating since they are not working on the same task. Thus, advanced students have some opportunity to show and explain their work, but there is little room for mathematical discussion during pair-share work.

Isa's typical lesson-Evaluation

In a whole-class setting, Isa encouraged individual students to show and explain their work. "I want to make them conscious of their own ideas in the mathematics lesson" she says.

Organising discussions between students during pair-share work seemed to be more difficult. "I am not satisfied with the way they do their homework and their writing is not neat. This takes a lot of my attention during pair-share work: checking their homework and written work. Besides which, I do not know how to organise discussions when the students are not working on the same task."

The researcher (MP) asked Isa what experiments she would like to try to stimulate discussion between students. She was thinking of a group test, that is, students individually preparing for a test which they take in groups of three or four. She would announce this to the students and tell them it was an experimental assessment.

Isa's experimental lesson

Isa lets her students take a group test for the chapter regarding measurement. She arranges the groups at the beginning of the lesson, taking into account whether students consider themselves well prepared or not (they are accustomed to reporting this to her at the beginning of each lesson). "I don't want them to profit from others who did prepare well. Besides, if all group members are badly prepared, they will have to work now." Groups are not allowed to discuss with other groups and in the large classroom there is enough space for all groups to work quietly. The test questions are not specially group questions; the students choose two of the three realistic problems to solve together (see Fig. 1). Moreover, in the final task, each group member is responsible for one column of questions; each group member has to write down the answers of a certain row, in order to make them all think of the exercises.

It is remarkable to see how intensively the students are collaborating: Most of them have prepared, so they have (thinking-) work to show. The time is limited, but they will show what they can. And they will get a group mark for their work, so it is worthwhile to be critical towards the work of peers and to improve the work. Students are enthusiastic. They notice that they are now collaborating with students with whom they have not worked before. 


\section{Task 1}

Lee is going to tile the bathroom. The wall is $2.4 \mathrm{~m}$ high and $4.5 \mathrm{~m}$ wide.

a) Calculate the surface of the wall using the rules you learned.

She used tiles of $16 \times 25 \mathrm{~cm}$.

b) Calculate how many tiles she needs.

The other wall in the bathroom has an area of $16 \mathrm{~m}^{2}$.

c) Calculate the width of this wall.

[Task 2 and task 3 comparable to task 1]

Write the answers in the columns below:

\begin{tabular}{|c|c|c|c|c|c|}
\hline \multicolumn{2}{|c|}{ 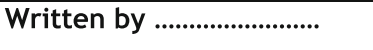 } & \multicolumn{2}{|c|}{ 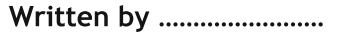 } & \multicolumn{2}{|c|}{ 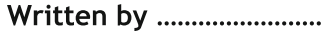 } \\
\hline 4 decametre $=$ & $\mathrm{m}$ & $350 \mathrm{~m}=$ & $\mathrm{cm}$ & $1324 \mathrm{dm}=$ & $\mathrm{km}$ \\
\hline $3.75 \mathrm{~m}^{2}=$ & ha & $3.2 \mathrm{~m}^{2}=$ & $\mathrm{cm}^{2}$ & $487 \mathrm{dm}^{3}=$ & $\mathrm{m}^{3}$ \\
\hline $8 \mathrm{cl}=$ & 1 & $73.3 \mathrm{~km}=$ & $\mathrm{cm}$ & 90 hectare $=$ & $\mathrm{m}^{2}$ \\
\hline $4 \mathrm{a}=$ & $\mathrm{Ca}$ & $0.65 \mathrm{~cm}=$ & $\mathrm{m}$ & 54.6 liter $=$ & $\mathrm{ml}$ \\
\hline $7 \mathrm{~m} 5 \mathrm{~cm}=$ & $\mathrm{dm}$ & $457.8 \mathrm{~cm}^{2}=$ & $\mathrm{dm}^{2}$ & $0.023 \mathrm{~km}^{2}=$ & $\mathrm{m}^{2}$ \\
\hline
\end{tabular}

Fig. 1 The test questions

An example of a dialogue between students is presented. Mike and Eva are collaborating on a mathematical task. They are discussing a "closed problem."

Eva: Why do you do that?

Mike: Well, look, cubic... so you multiply it by 1000 .

Eva: Why?

Mike: That's how you get to the metre.

Eva: Are you sure?

Mike: I will explain it.

Mike: Look, it is one step from $\mathrm{cm}$ to $\mathrm{dm}$, then another from $\mathrm{dm}$ to $\mathrm{m}$

Eva: Oh, yes.

Mike: So the answer is $504 \ldots$

It is interesting to see that a small, closed task can evoke regulating activities such as asking for explanations from students. This is in contrast to the criteria for learning materials in our previous research projects. But these activities might have something to do with the fact that the students will be rewarded for the test, so they want to be sure that the answer is correct.

Isa is walking through the classroom, keeping an eye on the work and the key activities of the groups. If groups are stuck on a problem, she may provide them with small hints, such as:

"Think of metres and cubic centimetres."

"What are you going to calculate?"

"How did you find out the content?"

"Use that assignment to solve this one." 
She also encourages the students to be critical of each other.

"Please say if something you write down is not correct."

"Make sure what your partners are writing down is correct."

Since it is a test, her interactions with students are minimal. Students accept this, whereas in normal lessons they may ask for more explanations from the teacher and hence diminish their own thinking.

After the lesson, Isa asked students how they experienced this test. Students highly valued the fact that they could explain their work to each other. They realised that they learned from working together with people they would not have chosen by themselves. The groups were assigned a group mark and 1 week later the students took an individual test. The marks of the individual tests and the group test were compared and appeared to be comparable.

\section{Isa's experimental lesson-Evaluation}

Isa was enthusiastic: "This group test really made them focus their thinking and students mentioned that they enjoyed being able to discuss their work with each other." In reply to the researcher's (MP) question about her way of guiding the students, Isa said that she provided some product help. "During a test I want to provide students with as much opportunity as possible as to show what they can do. I don't want them to get stuck on a detail. That's why I sometimes give them hints, to help them along. I also want them to discuss with each other, because when you can explain what you know to another person, you really understand it. I want them to collaborate intensively, so that's why I stimulate discussion."

This test appeared to be an excellent setting for discussion among students, for several reasons. First, most of the students had prepared the work, so they could really engage in the discussion. Second, the students felt involved as they got a mark for their work and there was a time limit. They really did their best. Third, the help of the teacher easily remained minimal, which is essential for both teacher and students as it was a test. Whereas in a regular lesson the absence of explanations by the teacher was often criticised by the students, this time they readily accepted that they had to find the answers by themselves.

\section{Results of Case II: John experiments with process help}

John has taught in a higher secondary education school for a few years and is interested in collaborative work. The majority of the teachers in his school teach in a traditional way, that is, students are sitting in pairs without interaction and the teacher gives individual help or whole-class explanations. One of John's mathematics colleagues has also experimented with collaborative learning, and he experienced student resistance when they were put into groups of four, as opposed to other lessons where students sat in rows. Students mentioned that they did not consider collaborative learning to be "real" mathematics. John was interested in joining the experiment, since he said that: "Often in my lessons I talk for longer than I would wish to. My question is really how to make my students more active in the lesson." 


\section{John's typical lesson}

The researcher (MP) is observing a $10^{\text {th }}$ grade lesson; students are 16 to 17 years old. They sit in pairs in rows, and they choose a different place every lesson, depending on which classroom they are in. John starts in a whole-class setting: "The rules on page 20 are essential for this chapter ..." He gives an example on the white board. "Does anyone have a question?" John regularly asks the students to show their work during this whole-class moment. During his explanations there are couples and groups of four who are discussing their homework and questions for the upcoming test. When this becomes too audible, John says "You may discuss mathematical tasks, but please do not talk about other things." Then, students continue with their homework and they ask John for help if they have a question. The researcher notices that John has a clear overview of which students are working and which are having off-task discussions. Students are collaborating from time to time, but John is not explicitly encouraging this. John: "When they have done their homework, they 'deserve' explanation. The danger is that students keep asking me for help and that I talk too much. It would be better for them to get on with their tasks and try to solve the problems themselves."

John's typical lesson-Evaluation

During whole-class moments, John performed some regulating activities by asking students to show their work. However, he rarely asked them to explain their work or to discuss each other's answers. Students do discuss their work with each other when they are preparing for a test during his whole-class explanations at the beginning of the lesson. The researcher (MP) suggested that when he allows them to do so; he might also mention to them that they learn from explaining their work to each other.

When students work independently they ask John for help and he provides them with mathematical hints. The researcher (MP) suggested to John that next time he makes it clear to his students that he wants them to discuss their work with each other if they have a question. He agreed to experiment with this response to students' questions.

\section{John's experimental lesson}

The next lesson develops largely the same as the typical lesson. Although John planned to react differently to students' questions, it takes some time for him to effect this change in practice. His "natural" tendency to help students by providing a mathematical hint is strong. When he finally succeeds in staying away from the mathematical content of the question and stimulating the interaction between his students, they begin to really discuss their mathematical tasks. This encourages John to respond in the same way with other students. A little later, several groups of students are eagerly discussing together.

\section{John's experimental lesson-Evaluation}

Although telling students to discuss the problem with their neighbour might seem a simple request, it appeared to be quite a step for this teacher not to provide students with mathematical hints. In the reflection afterwards, John said that he indeed had to convince himself, but he had been surprised by the result. "I gave them an idea (to 
collaborate) which they would never have thought of themselves, and it worked. They have everything to gain. Even without complicated structures and tasks in the classroom, students can very easily make use of the person sitting next to them."

The next step for John could be to remind his students what happened in this lesson and make them conscious of it, and tell them that they learn from explaining their work to others.

\section{Results of Case III: Linda experiments and has her doubts}

Linda is an experienced teacher, open for didactical change. She knows that the researcher $(\mathrm{RD})$ has expertise in collaborative learning of mathematics, so when the researcher asked if she could observe her teaching to look for her ways of shaping discussion between students, Linda immediately agreed. The first observation would be of a normal lesson and then we would discuss how she shaped or could shape interactive moments between students, and in particular mathematical reasoning.

\section{Linda's typical lesson}

The $11^{\text {th }}$ grade class is in a large, light classroom with mathematics posters on the walls. The tables are big and heavy, and 27 students aged 16 to 17 are sitting next to each other in rows of two, three or four. Linda tells them that she has painted the fence and that she wants to clean the brush, but there is only a little bit of turpentine. "You have to put it in the fridge," a boy in the front suggests. Linda smiles, but she wants to talk about dilution and she asks the students if it is better to use the turpentine all at once, or to divide it into two small cups. This practical problem is the start of the subject of limits in which $e$ as limit is dominant.

"Work on the problem by yourself or with your neighbour," says Linda. The researcher hears a lot of explaining. Linda is helping a lot too and it is remarkable that whenever she is near certain students, they start to ask her questions. The researcher does not hear her asking for reactions to the questions from other students. So Linda does not treat students who collaborate as a unit. Her explanation is subtle, though. She tries to help students by asking questions.

"Did you check your answer with your neighbours?" Linda asks, as if she has read the researchers' mind! She ends the lesson with a classical discussion, strongly led by her. She manages to end the lesson with Euler and shows him on a historical year line with famous mathematicians above the blackboard.

\section{Linda's typical lesson-Evaluation}

The researcher showed Linda her observational notes in relation to the regulating and key activities of the students. Linda was sensitive to the missed chances to stimulate discussion. She was also touched by the fact that students "used" her as soon as she was close by. The researcher and Linda discussed how she could make her students more conscious of what they could gain from discussion. The researcher gave her the golden rules, which were developed in earlier research (Dekker and Elshout-Mohr 2004): 
Show each other your work!

otherwise you don't have anything to discuss

Explain your work to each other!

because that makes you learn

Give each other critique!

because that improves the work

\section{Linda's experimental lesson}

Linda has brought two home-made apple pies with her and after she says that they have to finish the chapter on exponential and logarithmic functions this lesson, and that the researcher is there again to observe their discussions, she concentrates on dividing the pies and the students start working. She doesn't mention the golden rules, but it is a clever way to stimulate discussion and to make the researcher an observing guard! It smells delicious in the classroom and Linda is clearly not available to give help. The students start to collaborate and the researcher hears some discussions. A group of three girls in front of the teacher are very busy together; a group of girls behind her are talking about anything but mathematics. Linda distributes the pies.

"Look at the examples in the book," Linda responds to a question.

"Ask Martin" the researcher hears her say, "it is good for Martin too..."

"Barbara, have you done anything?" Linda asks.

"Not much," Barbara says.

"You have two teachers sitting next to you," Linda reacts.

"Do you have the card with formulas? Investigate it, the three of you."

Linda observes two boys at the back who are deep in discussion. They indicate that they do not want any help from her.

Several small groups are very busy discussing. The researcher also sees students working alone. At the end Linda asks the students if they enjoyed discussing. There are positive reactions and the two boys at the back are clearly excited that they managed to solve the problems together without any help.

At the end of the lesson Linda says to the researcher: "I found this really very hard."

Linda's experimental lesson-Evaluation

The researcher interviewed Linda after the lesson.

"At the end of the lesson you told me that you found it hard."

"Yes, because I like to explain, especially when I see those questioning eyes.

When they are stuck and want you to help them with the next step, I very much

like being able to explain it to them. I like mathematics very much and I want 
to know how my students react. I want to help them very gradually without telling them exactly what to do, but I want to be there to see how the process evolves. Now I really had to say 'ask your neighbour,' and walk away as quickly as possible, otherwise they kept asking me. I don't feel that I did a good job."

\section{"You had the feeling that you were not allowed to explain."}

"I wanted to stay away from it, and that was very hard. There are some very good students. Tamar is very good, but she had a question. I told her that maybe Rica could help her. Rica is not that strong and she isn't as far as Tamar, because Tamar gets on with her work. Tamar is usually the one who explains everything to the other two, Iris and Rica. And then she had a question for me, but I don't know how that ended and I don't like that feeling, not knowing whether or not she understood it in the end."

\section{"Did you see an effect of your different role?"}

"Well, that was funny. I found it very hard, but at the end I saw students discussing more with each other and sometimes that worked very well; they really started to ask each other to explain and they helped each other. Like at the end when I asked for their opinion, there was one couple, two boys, who said they had collaborated very successfully by showing and explaining their work to each other. But they were working on the same problem. Maybe that is crucial. It might have been different if one was much further than the other but still had to help another person, even though they were involved with their own problem; they would then have had to move over to another problem. I am the one who has expertise to deal with all the problems at the same time."

Later the researcher listened to her audiotape to find the fragment where Linda "helps" Tamar by involving Rica. The researcher is curious if Linda's doubts make sense.

Tamar, Rica and Iris

Tamar: How can one ever take a primitive from this? It isn't really explained. Linda: Isn't it?

Tamar: No, they explain it only for one divided by $\mathrm{x}$, but not really for something with a minus.

Linda: [to Rica] Where are you?

Rica: ...

Linda: It may be nice if Rica has a look at where you're getting stuck. You are very good, but Rica may see why you're having trouble. She looks at different things. Why is this problem more difficult than that one? Maybe it is only something small that you don't see and Rica does.

Linda goes away.

Iris: So, now you are allowed to explain, how nice. 
[Laughter.]

Rica: What is a primitive?

Tamar looks into the booklet with solutions.

Tamar: It has to be one sixth, it has to be this.

Iris: Is one sixth two times? ... so maybe if you... that I understand

Tamar: I understand that there is a minus.. But why it is one sixth?

Rica: Oh, maybe it is one half, because there you divide by three...

Iris: But the derivative of minus two is... if you take the derivative from this, then that is minus two, and if that minus two times one divided by three, that is... one sixth and then you have two...

Tamar: Sure, do you know another way to get one sixth? One divided by six! Iris: Yeeeeeah, but here is a three, if you... just like the one with one hundredth, then you didn't do one hundredth, but you did put it down.

Tamar: Shall I just put it down?

Iris: Just act as if you understand.

Tamar: Well, I don't understand anything about it. I'm already getting stuck with the nextone. What is the primitive of this?

Iris: Of only this little piece? The primitive or the derivative?

Tamar: Primitive, plus one

Iris: Oh, if you know what the primitive is... ...

Tamar: (...)

Iris: No, just have a look...

Maybe Rica did not really get involved, but Iris did, and she revealed herself as an explainer. It is unusual for Tamar not to be the explainer, but a real breakthrough in this little group. And all because of Linda's clever action!

\section{Conclusions and discussion}

The aim of the study was to find out how mathematical teachers in their daily practice can encourage their students to perform key activities for mathematical level-raising (to show, explain, justify and reconstruct one's work) (Dekker and Elshout-Mohr 1998). In Dutch classrooms almost every lesson starts with an oral introduction by the teacher in a whole-class setting, consisting of explanation of the homework and introduction of a new mathematical issue. Then students work independently, sitting in pairs, on their mathematical tasks. The teacher walks through the classroom to answer the students' questions. Our question was: How can teachers realise mathematical discussions between students in this daily practice? First we examined what teachers already did in their daily classrooms to enhance key activities.

Key activities in daily practice

We observed several ways in which the three teachers already evoked mathematical discussions between their students. During the introduction of the lesson, the observed teachers often asked students to show their work by posing questions in 
general ("What is the derivative of $x^{2}$ ?," "What is the most effective way to clean my brush using as little turpentine as possible?") or by asking a specific student to show his or her answer. However, students were rarely asked to react to each other or given the chance to first discuss their problem-solving strategies with each other. We did not observe teachers asking students for explanations of their work or asking them to ask other students to critique their work in the whole-class setting. The teachers mentioned "working with peers" to students as a possible way of doing their work and this occurred. It seemed to be tolerated, rather than enthusiastically promoted to the students as an effective way to sharpen their own thoughts and ideas. Overall, teachers invited students to show their work in the whole-class setting, but they did not make use of the opportunities to start mathematical discussions between students.

When students were working independently and asked the teacher for help, the teacher did not usually involve peers. They gave explanations or subtle mathematical hints to the student who asked the question. One teacher experienced that the questions arose while she walked through the classroom, as if that evoked students to ask her for help. Another teacher considered providing help as a "reward" for students who put a lot of effort into their homework. Altogether, although small discussions in classrooms sometimes did take place, there was a lack of "shared understanding" between students and teacher regarding the fact that these were activities that could be learnt from. However, the teacher's hints were generally considered as crucial for learning. This phenomenon has also been observed in other research (Barkatsas and Malone 2005; Pijls et al. 2007b).

\section{Experiments with process help}

The three teachers developed an intervention to evoke key activities. The first teacher did so by offering students an assessment to be completed in groups. The test served as a setting for discussion between students. This formative use of assessment (Harlen et al. 1992) evoked the performance of key activities due to the fact that students had prepared for the test (which enabled them to explain their work much better than without preparation) and the fact that they got a "mark" for it (which motivated them to look for the right answer). Furthermore, the fact that the groups were arranged by the teacher and that the time was limited also stimulated discussion between students. The group test thus served as a tool to make the students perform key activities and to get insight into the students' thinking processes. The students' solution-finding processes were made visible, as Even (2005) mentioned in her study on contemporary assessment techniques. Another way to stress to students the importance of key activities in the mathematics lesson might be to assess the showing, explaining, and possibly also the justifying and reconstructing of their work activities. This self-assessment and meta-cognition process could be incorporated into the collaborative learning activity so that students regularly reflect on key activities such as how well they shared their ideas and justified their problem-solving strategies.

The second teacher intentionally refrained from providing the answer or a hint when a pair of students asked him for help, but explicitly directed them to each other. As Ding et al. (2007) found, this is not at all easy for teachers; there is a strong 
tendency to explain. However, this intervention led to unusual discussions between small groups of students in the mathematics lesson.

The third teacher went even further in evoking explanations from her students. She explicitly told a student, who had never been expected to explain her work before, to explain a mathematical task to her peers. This led to an unexpected discussion between three students, in which the student who usually explained listened, and the third mainly explained. By asking the "weak" student to explain, the teacher made clear that the act of explaining was more important than "providing the right answer." Students could learn that by explaining their work, they might learn something themselves. For this teacher it was helpful that the discussion between students was audio taped, because this allowed her to check what happened in the small group discussion.

\section{Process help: some barriers}

What can we conclude from the description and the analysis of the three cases? It was really hard for all three teachers to change their role, despite all three having agreed on changing their role and on being influenced in the way to do that. The first teacher actually did provide some mathematical hints, although limited through the setting of an assessment. It took some effort and time for the other two to "resist their natural inclination to tell students information, make the task simpler, or step in and do part of the task" (Wood 2001, p.116). The third teacher, in spite of positive effects, kept insisting that the setting should be different: that is, students working on the same task at the same time. Moreover, she expressed her own preference for giving students explanations. Many mathematics teachers like to explain; they feel it is their "mission." So it is a big step to ask these teachers to change their role and stimulate students to give each other explanations. A change of setting is one way of justifying the change of role for their students. A change of role during the normal lessons seems simple, but implies a more radical change in the didactical contract they have with their students (Brousseau 1997).

\section{Process help: some possibilities}

The experiments with process help also yielded new opportunities for discussion in the mathematics lesson. The first teacher discovered that her students were enthusiastic about their mathematical discussions; the second teacher immediately felt the positive effect of students discussing their work with each other and saw opportunities to incorporate this in his normal lessons. This relatively small intervention could have remarkable effects. In our case studies we focussed on the first experiences with this teaching method. When teachers become aware of the effect of their (new) behaviour, they may become interested in integrating new strategies into their teaching. In a longer trajectory teachers may have the opportunity to develop innovative practices, experiment, reflect and share ideas (Swan 2006; de Geest 2007). Whether a teacher succeeds in implementing reform practices or not depends on many factors (Cady et al. 2006).

A next step after trying out process help in the classroom could be to make the students aware of the interesting discussions which occurred during this "special" lesson and the fact that one learns from explaining to a peer. Students and teachers would therefore become conscious that discussing thoughts and explaining ideas is essential in 
mathematics lessons. We do not mean that math teachers should only give process help during their lessons, but the tendency to provide mathematical information appears to be so strong that it would be worthwhile for them to incorporate process help alongside content/product help to provide a balanced mathematics pedagogy.

Open Access This article is distributed under the terms of the Creative Commons Attribution Noncommercial License which permits any noncommercial use, distribution, and reproduction in any medium, provided the original author(s) and source are credited.

\section{References}

Amit, M., \& Fried, M. (2005). Authority and authority relations in mathematics education: a view from an $8^{\text {th }}$ grade classroom. Educational Studies in Mathematics, 58, 145-168.

Barkatsas, A., \& Malone, J. (2005). A typology of mathematics teachers' beliefs about teaching and learning mathematics and instructional practices. Mathematics Education Research Journal, 17(2), 69-90.

Brousseau, G. (1997). Theory of didactical situations in mathematics. Dordrecht: Kluwer Academic Publishers.

Cady, J., Meier, S. L., \& Lubinski, C. A. (2006). The mathematical tale of two teachers: a longitudinal study relating mathematics instructional practices to level of intellectual development. Mathematics Research Journal, 18(1), 3-26.

de Geest, E. (2007). Many right answers. Learning in mathematics through speaking and listening. London: The Basic Skills Agency.

Dekker, R., \& Elshout-Mohr, M. (1998). A process model for interaction and mathematical level-raising. Educational Studies in Mathematics, 35(3), 303-314.

Dekker, R., \& Elshout-Mohr, M. (2004). Teacher interventions aimed at mathematical level-raising during collaborative learning. Educational Studies in Mathematics, 56(1), 39-65.

Dekker, R., Elshout-Mohr, M., \& Wood, R. (2004). Working together on assignments: Multiple analysis of learning events. In J. van der Linden \& P. Renshaw (Eds.), Dialogic learning (pp.145-170). Dordrecht, The Netherlands: Kluwer Academic Publishers.

Ding, M., Li, X., Piccolo, D., \& Kulm, G. (2007). Teacher interventions in cooperative learning mathematics classes. The Journal of Educational Research, 100(3), 162-175.

Even, R. (2005). Using assessment to inform instructional decisions: how hard can it be? Mathematics Education Research Journal, 17(3), 45-61.

Freudenthal, H. (1973). Mathematics as an educational task. Dordrecht: Reidel.

Gillies, R. M., \& Khan, A. (2008). The effects of teacher discourse on students' discourse, problem-solving and reasoning during cooperative learning. International Journal of Educational Research, 47(6), 323-340.

Harlen, W., Gipps, C., Broadfoot, P., \& Nuttall, D. (1992). Assessment and the improvement of education. Curriculum Journal, 3(3), 217-225.

Hodge, L. (2008). Student roles and mathematical competence in two contrasting elementary classes. Mathematics Education Research Journal, 20(1), 32-51.

Hoek, D. (2007). Ontwikkeling van een leer ecologie voor samenwerkend leren [Development of a learning ecology for collaborative learning]. Pedagogische Studiën, 84(5), 407-417.

Palha, S. (2008). Inhoudelijk praten over wiskunde. Hoe doe je dat? [Discussing Mathematics: How do you do that?]. Utrecht: Universiteit Utrecht.

Peressini, D., \& Knuth, E. (1998). Why are you talking when you could be listening? The role of discourse in the professional development of mathematics teachers. Teaching and Teacher Education, 14(1), 107-125.

Pijls, M. (2007). Collaborative mathematical investigations with the computer: Learning materials and teacher help. Amsterdam: Universiteit van Amsterdam, Graduate School of Teaching and Learning.

Pijls, M., Dekker, R., \& Van Hout-Wolters, B. (2007a). Reconstruction of a collaborative mathematical learning process. Educational Studies in Mathematics, 65(3), 309-329.

Pijls, M., Dekker, R., \& Van Hout-Wolters, B. (2007b). Teacher help for collaborative mathematical levelraising. Learning Environments Research, 10(3), 223-240.

Stigler, J., \& Hiebert, J. (1999). The teaching gap: best ideas from the world's teachers for improving education in the classroom. New York: The Free Press. 
Swan, M. (2006). Collaborative learning in mathematics; a challenge to our beliefs and practices. London: Learning and Skills Network.

Walshaw, M., \& Anthony, G. (2008). The teacher's role in classroom discourse: A review of recent research into mathematics classrooms. Review of Educational Research, 78(3), 516-551.

Webb, N. M. (1991). Task-related verbal interaction and mathematics learning in small groups. Journal for Research in Mathematics Education, 22, 366-389.

Webb, N. M., Franke, M. L., Ing, M., Chan, A., De, T., Freund, D., \& Battey, D. (2008). The role of teacher instructional practices in student collaboration. Contemporary Educational Psychology, 33, 360-381.

Wood, T. (2001). Teaching differently: creating opportunities for learning mathematics. Theory into Practice, 40(2), 110-117. 